\title{
Teología de y en la historia: sobre la pretensión historiológica de una teología de los signos del tiempo
}

\author{
Juan Noemi \\ FACULTAD DE TEOLOGÍA \\ PONTIFICIA UNIVERSIDAD CATÓLICA DE CHILE
}

El título de nuestro artículo ${ }^{1}$ preestablece una distinción básica entre historia y teología para luego preguntarse si entre ambos términos cabe ayuda mutua o independencia. Ahora bien, en los últimos años, es posible visualizar en lo referente a la polaridad historia-teología, un desplazamiento así como el perfilarse de un imperativo que se le adjunta. Al hablar de desplazamiento nos referimos a un transitar dialéctico (de ida y vuelta) de una teología de la historia a una teología en la historia y el imperativo propuesto es el de articular una teología que se valide razonablemente como teología de la historia y simultáneamente en la historia. Quisiera recalcar que no se trata simplemente del tránsito o paso de una teología de la historia a otra teología en la historia sino que persiste, en este desplazamiento como imperativo, el articular una teología en la historia que al mismo tiempo se valide como teología de la historia. Solamente así se posibilita un acceso que atienda adecuadamente a la historicidad en su doble dimensión, es decir, tanto subjetivamente (en la historia) como objetivamente (de la historia). Solamente encarando esta simultaneidad de un de y un en la historia se corresponde razonablemente al desafío de dar razón de nuestra esperanza hoy en día, dado que solamente pensando la unidad que sustenta y sostiene la alteridad de un de y un en la historia cobra sentido la distinción que se haga entre historia y teología.

Ponencia presentada en el Seminario interno de profesores de la Facultad de Teología de la Universidad Católica de Chile 2010, titulado «Historia y Teología. ¿̇yuda mutua o independencia?». 


\section{Teología de la historia como desafio persistente}

La elaboración de una teología de la historia ${ }^{2}$ persiste como uno de los grandes desafíos para este siglo. Retrospectivamente y de manera muy somera podría decirse que desde el surgir de la modernidad hasta hoy día es posible distinguir tres modelos fundamentales en los cuales se articula la experiencia que el hombre hace de la historia. El primero corresponde a la experiencia antropocéntrica que es propia de la Ilustración y comporta el destronamiento de la providencia divina de la sede unívoca de significado en que la sitúa la teología premoderna de la historia. El segundo concierne a la reacción romántica que descubre en el pasado una nueva positividad y pone en evidencia la unilateralidad de las utopías ilustradas. Para el tercer modelo la historia deviene y se radicaliza como historicidad, es decir, cualidad que determina todos los momentos del círculo hermenéutico y entonces compromete la misma posibilidad del entender en cuanto tal.

Un rasgo común a estos tres modelos es el plantearse, al menos implícitamente, como ensayos de filosofía de la historia. La expresión filosofía de la historia la encontramos por primera vez en el escrito de Voltaire de 1756 Essais sur les moeurs et l'esprit des nations. Con ella se designa una aproximación diversa a la teonómica que se articula teocéntricamente y que hasta entonces había sido la habitual para pensar la historia. Valga la pena recordar lo que propone K. Löwith al respecto ${ }^{3}$ : referirse a la filosofía de la historia como algo diverso a la teología de la historia comporta una distinción relativa dado que la posibilidad de hablar de la historia en singular como objeto pensable, antes que el resultado y la evidencia a la que se llega por medio de una prueba racional, es algo que se recibe como un traditum que se sostiene como proclamación de fe del teocentrismo judeocristiano. A este respecto es ilustrativo recordar el ensayo de Giambattista Vico en su Scienza Nuova cuya primera edición remonta a 1725 y donde se propone desarrollar una «teología civil racional de la providencia». El ensayo de Vico constituye el antecedente que posibilita a Voltaire presentarse como «filósofo e historiador» y contraponer su ensayo al Discours sur

2 La expresión «teología de la historia» habría sido utilizada por primera vez en 1906 por A. Schweitzer en referencia al planteo de E. Troeltsch, solo desde entonces se generalizaría, cf. T. RENDTORFF, «Geschichtstheologie» en Historisches Wörterbuch der Philosophie 3, 439.

3 Cf. K. Löwith, El sentido de la historia (Madrid 1968) traducción del original publicado en Chicago en 1949 con el título Meaning in History. 
l'Histoire Universelle de J. B. Bossuet en 1681 que se plantea todavía en una perspectiva teocéntrica y agustiniana.

A juicio de Löwith, la pretensión filosófica de la Ilustración para pensar la historia comporta una doble ambigüedad, a saber, de origen y en su resultado. La ambigüedad de origen reside en que al referirse a la historia como objeto de una razón que se sirve del propio entendimiento y emancipada de tutores como exige Kant, entonces, tal razón se confronta con un objeto que no es sustentable a partir de dicha razón y ante el cual se comporta de manera unilateralmente crítica. K. Löwith hace hincapié en que la filosofía de la historia (en singular) solo es pensable a partir del presupuesto teonómico fundamentado por una teología de la historia tal como esta se dio desde Agustín a Bossuet. En cuanto a la ambigüedad del resultado consiste en que el desarrollo de esta filosofía de la historia queda confrontada a la aporía de un relativismo historicista como único escape de la bybris hegeliana ${ }^{4}$.

Explicitar los «presupuestos teológicos de la filosofía de la historia» como lo hace K. Löwith no pretende de ningún modo descalificar o minimizar la envergadura de la pregunta que plantea la experiencia de historia, solo se trata de asumirla también en toda la complejidad y resonancia metafísica que conlleva como bien lo plantea Schelling. En realidad ya sea para el filósofo como también para el teólogo se trata de un problema fundamental en cuanto sujeto que piensa y no se conforma con meros postulados dispersos que arbitrariamente impondría una determinada fe religiosa. Como lo sintetiza muy bien W. Kasper: «La realidad debe ser entendida no solo temporalmente sino históricamente, es decir, no podemos nunca hablar de la realidad de manera puramente objetiva sino solamente de tal manera que el sujeto que interpreta y transforma la realidad se hace parte integrante (miteinbezogen) de la misma. La realidad se constituye solo en el juego dialéctico de sujeto y objeto, remite al hombre y es referida a partir del hombre; ella se encuentra a la vez estructurada como realidad histórica antropocéntricamente» ${ }^{5}$.

$4 \quad \mathrm{Al}$ respecto se puede ver lo que anoto en $\dot{e}$ Es la esperanza cristiana liberadora? (Santiago 1990) 73-103, especialmente 92 y ss.

5 «Die Wirklichkeit muss nicht nur zeitlich, sondern geschichtlich verstanden werden, d.h. wir können nie rein objektiv von der Wirklichkeit sprechen, sondern lediglich in einer Weise, in der das Subjekt, das die Wirklichkeit deutet und gestaltet, miteinbezogen ist. Wirklichkeit konstituiert sich erst im dialektischen Zusammenspiel von Subjekt und Objekt; sie ist auf del Menschen hin und von ihm her; sie ist als geschicht- 
Si se atiende a las reflexiones de Löwith que acabamos de esbozar, no debería extrañar que en un reciente comentario teológico del Concilio $\mathrm{Va}$ ticano II se plantee como programa de búsqueda conciliar la elaboración de una «teología de la historia en base a los signos de los tiempos» (Geschichtstheologie aus der Zeichen der Zeit) ${ }^{6}$. Todavía más, la búsqueda de la unidad que sostenga adecuadamente la diferencia y distinción que se haga entre historia y teología, encuentra una expresión concreta y emergente como proyecto no solo para una teología de los signos de los tiempos, sino que más radicalmente coincide con la necesidad de repensar la unidad dinámica que sostenga la multiplicidad de lo real. Al respecto, es ilustrativa la advertencia inicial que hace Charles Taylor a propósito de una conferencia titulada «¿Una modernidad católica?»: «El título -escribe este pensador canadiense- podría haberse invertido; esta conferencia pudo haberse titulado "Un catolicismo moderno?". Pero tal es la fuerza del adjetivo moderno en nuestra cultura que uno inmediatamente puede dar la sensación que el objeto de mi investigación fuera un nuevo, mejor y mayor catolicismo con el ánimo de reemplazar todas esas variadas y anticuadas formas que nublan nuestro pasado. Pero investigar esto habría sido perseguir una quimera, un monstruo que no puede existir en la naturaleza de las cosas. No puede existir a causa de lo que finalmente significa "catolicismo" para mí. Por eso empezaré diciendo una palabra al respecto. "Id y enseñad a todas las naciones" ¿Cómo entender este mandato? La forma fácil, aquella en la cual ha sido a menudo entendida, ha sido tomar el punto de vista general de los que somos cristianos y empeñarse en estimarlo conveniente para otras naciones y culturas. Pero esto viola uno de los principios básicos del catolicismo. Prefiero tomar la palabra original katholou en dos sentidos interrelacionados, ambos comprenden universalidad y totalidad; podríamos decir universalidad a través de totalidad» ${ }^{7}$. A renglón seguido Taylor se explaya: «La redención tiene lugar a través de la encarnación, la trama de la vida de Dios en las vidas humanas, pero estas vidas humanas son diferentes, plurales,

liche Wirklichket zugleich anthropozentrissch strukturiert». «Die Schöpfungslehre in der gegenwärtigen Diskussion» en Konturen heutiger Theologie. (Bitter- Miller 1976) 96.

6 Nos referimos al estudio de H. J. SANDER, «El singular actuar histórico de Dios»-una pregunta de la plural topología de los "signos del tiempo"»-, en Herders Theologischer Kommentar zum zweiten Vatikanischen Kon₹il: Zusammenschau und Perspektiven 5 (Freiburg 2006) 134-147.

7 J. L. Heft, A catholic modernity? Charles Taylor's Marianist Award Lecture (Oxford 1999) 13-14. 
irreductibles entre ellas. Redención-encarnación trae consigo reconciliación, una especie de unidad. Esta es la unidad de diversos seres que parecen mostrar que no pueden alcanzar la totalidad por sí solos, que su complementariedad es esencial, más aún que se trata de existencias que deben aceptar que son esencialmente idénticas. O quizá deberíamos decir: complementariedad e identidad que ambas serán partes de una unidad última. Nuestra gran tentación histórica ha sido olvidar la complementariedad para ir directamente en búsqueda de la uniformidad, haciendo de la mayor cantidad posible de personas "buenos católicos"; este proceso determina un fracaso (en el logro) de la catolicidad: fracaso de la catolicidad porque no se atiende a la totalidad; unidad comprada con el precio de suprimir algo de la diversidad de la humanidad creada por Dios; unidad de las partes disfrazada como totalidad. Se trata de una universalidad sin totalidad y por eso de un catolicismo no verdadero» ${ }^{8}$. El desafío de conjugar «universalidad a través de totalidad» (universality through wholeness) remite a pensar lo real atendiendo a la dinámica unidad de lo múltiple. Aunque no se trata de un requerimiento exclusivo de la modernidad tiene una especial astringencia para un pensar teológico que no se paraliza en el inmediatismo pastoral y reconoce que para la teología hacerse comprensible supone un esfuerzo especulativo insoslayable. Se trata de reconocer, con Kasper, no solo el estructurarse antropocéntricamente de lo real sino también de superar representarse la realidad de Dios como otredad objetual y más bien reconocerlo como realidad non aliud (no-otra). Esta no-otredad de Dios es requerida por la afirmación de su trascendencia que no se contrapone a su inmanencia sino que la sustenta y compenetra.

De acuerdo a lo anterior tendríamos que el desafío que enfrenta una teología de los signos de los tiempos es el de conjugar totalidad teológica a través de universalidad histórica. La teología de los signos de los tiempos pretende hablar de Dios y de la historia no como realidades disociadas o disociables sino integralmente. Validarse como interpretación de Dios no al margen de la historia sino como interpretación de la misma?. Tal es el talante hermenéutico que supera no solo una contraposición sino tam-

8 O.a.c. 14

$9 \mathrm{Al}$ respecto se puede ver el incisivo planteo que hace P. HüNERMAnN, «La acción de Dios en la historia. Teología como interpretatio temporis» en J. O. BEOzzo - P. HüNERMANN - C. SChickendantz, Nuevas pobrezas e identidades emergentes. Signos de los tiempos en América Latina (Córdoba 2006) 17-59. 
bién una superposición entre discurso teológico y discurso histórico. Este sería el paradigma transparente y receptivo del carácter intrínsecamente histórico del discurso bíblico que nunca habla de Dios en abstracto sino como realidad que es aconteciendo históricamente. Sobre la radicalización del «talante histórico de la teología latinoamericana» con posterioridad al Concilio Vaticano II y sobre «el imperativo de historicidad» que se autoimpone nos hemos explayado con anterioridad ${ }^{10}$. Baste aquí recordar que no estamos pues ante una programa teológico parcial sino uno que comporta un replanteo radical del discurso teológico como mediación entre la unidad y pluralidad a la que remite un discurso sobre Dios y la historia. No se trata de negar la validez de distinguir entre Dios e historia sino de superar un dualismo que los objetualiza para abocarse a pensar la unidad de lo que -precisamente distinguiéndolos- los une y relaciona. De lo que se trata es de pensar a Dios como distinto pero a la vez non aliud de la historia, es decir, pensarlo como la unidad que sostiene y así da sentido a la distinción entre historia y Dios ${ }^{11}$.

Recentramiento pneumatológico de la cristología como requisito pendiente para una teología de la historia y en la bistoria

De acuerdo al enfoque de Nicolás de Cusa el theologos, o discurso teológico, no alcanza su realidad como otredad objetualizada sino como «idéntico absoluto» ${ }^{12}$, es decir: «Lo idéntico no es algo así como un ente que "hace" otros entes; más bien es lo idéntico en todo lo diverso, es la unidad que solo es en lo plural... lo idéntico es únicamente en las partes y solo así es lo idéntico. Lo idéntico no puede ser captado con las categorías y determinaciones del ente dado. Lo idéntico no es lo mismo desde otro, porque entonces no sería lo idéntico absoluto. No puede determinarse desde algo otro: es lo indeterminado absoluto y solo como tal puede ser fundamento de toda determinación; o sea, lo idéntico es la determinabilidad de lo determinado, pero la determinabilidad no es ella misma una determinación» ${ }^{13}$.

10 Cf. J. Noemi - F. Castillo, Teología Latinoamericana. Rasgos imperativos y desafio. Liberación y praxis (Santiago 1998) 30-39, 50-52.

11 Cf. J. Noemi, «El horizonte dogmático-histórico y eclesial-universal de una teología de los signos de los tiempos» en Multifariam. Homenaje a los Profs. A. Meis, A. Bentué y S. Silva (Santiago 2010) 509-520.

12 Me apoyo en el planteo de R. Hüntelmann, «El Cusano y la primera filosofía moderna de la creación» en Anuario Filosófico (1995) 28 649-670.

13 O.a.c. $652-653$ 
Sin embargo, cuando el hombre intenta enunciar un theologos no puede dejar de decirse a sí mismo. Esta constatación tiene una dimensión doble. Negativamente deriva de la finitud y ambigüedad del lenguaje humano. Positivamente corresponde, al menos en las coordenadas del judeocristianismo, a una dimensión del propio acontecer de Dios.

Con respecto a la dimensión negativa baste recordar que toda teología es y permanece siempre como un discurso humano, habla de Dios pero es insuperablemente el discurso de una persona humana concreta. Por más que el teólogo intente situarse en la perspectiva y horizonte del objeto, o-como suele decirse- hablar desde Dios, su discurso es un discurso humano condicionado y provisorio, relativo a la condición del hombre que habla. El teólogo que piensa poder hablar desde Dios y no reconoce que, sin embargo, habla desde sí mismo, no solo se autoengaña, sino que corre el riesgo de pervertir su teología en una desmesura insostenible expuesta al fanatismo y fetichismo religiosos. Dios no es sustituible como el único sujeto adecuado de decirse a sí mismo. Dios no cabe en ningún discurso humano. De allí el momento apofático que debería respetar toda teología, el reconocimiento de una teología negativa no como un límite externo sino como una dimensión propia e insuperable del mismo decir a Dios ${ }^{14}$. Solo existen teologías con minúscula. Las teologías que, intentando superar su provisoriedad se autoprograman desde Dios, comprometen la dignidad del propio discurso. Solo cabe y tiene sentido postular un discurso desde Dios en el hombre. En cuanto tal la teología es insuperablemente discurso humano, aproximativo, provisorio y fragmentario. Reconocerlo es integrar un límite no como mera negatividad externa, sino como condición de posibilidad positiva de que el hombre puede verdaderamente decir y referirse a la realidad de Dios.

Con respecto a la dimensión positiva que le concierne al theologos baste señalar que en el yavismo primitivo la prohibición de hacerse imágenes de Dios (Ex 20, 3-5; Dt 5, 7-9) no es más que una consecuencia del reconocimiento de Yavé como una realidad que abandona la trascendencia abstracta de la divinidad e interviene y acontece en la inmanencia histórica de

14 Como dice A. Solignac: «La convicción de que el espíritu humano y el lenjuaje son impotentes para expresar a Dios tal como es permanece una constante de todo pensamiento teológico digno de este nombre», «Théologie Négative» en Dictionnaire de Spiritualité XV (París 1991) 515. 
Israel: «Soy yo, Yavé, tu Dios, el que te hizo salir de Egipto» ${ }^{15}$. La negación de otras divinidades, la prohibición de hacer imágenes de Dios es pues la consecuencia de un antecedente positivo: Dios no existe como trascendencia abstracta y objetualizada, sino como acontecer concreto que se compromete y entrega en la inmanencia de la historia de Israel.

Los escritos neotestamentarios tampoco deben leerse como aval o sanción de una determinada teología monolítica o monopólica. Constituyen más bien una recopilación de varias y diversas teologías que expresan el acontecer de Dios en Jesús de Nazareth. Las de Pablo, Lucas, Marcos y Mateo siguen siendo teologías con minúscula. Ni siquiera el Nuevo Testamento en su conjunto podría considerarse como la teología sino como el testimonio de que la persona e historia de Jesús es el único theologos definitivo y acabado de Dios (Heb 1, 1-4).

Es así como de Dios se habla -en el judeocristianismo- no solo como acontecimiento en favor de los hombres (y no como supuesto correlato al concepto abstracto y objetual que de Él pudiésemos hacernos) sino que, además, se nos atestigua que Dios aconteció concretamente en un hombre, que es la historia de Jesús la que nos dice al verdadero Dios, que -todavía más- la historia del verdaderamente hombre es la historia del verdaderamente Dios. Según lo anterior, Dios no ha querido ni nos pide una teología desde Dios, más bien, positivamente nos enseña que Dios ha querido libremente decirse y darse desde la historia de un pueblo y de un hombre concreto, desde Israel y Jesús. Con ello no se niega la apertura y ansia de Dios que se da en cada hombre, sino que se nos previene de evitar y caer en la concupiscencia religiosa. Para el judeocristianismo, el desde el hombre (o si se prefiere el desde Dios en el hombre) no es fatalidad derivada de nuestra finitud, sino designio positivo escogido por Dios mismo. Es preciso hablar desde el hombre porque Él quiso hablarnos así, porque Él hizo suya insuperablemente nuestra finitud al hacerse hombre. De este modo Dios no se confunde (inconfuse) con el hombre pero indivisiblemente e inseparablemente ha hecho suyo lo nuestro. Se nos enseña que, aunque la teología no se confunde con la antropología, queda - gracias al acontecer de Dios en Jesús- indivise et inseparabiliter relacionada con esta. Pretender hablar desde Dios al margen del hombre es querer so-

15 En Dt 5, 3 se hace presente este dinamismo de alianza: «No es con vuestros padres que Yavé concluyó una alianza sino con vosotros que estáis vivos». 
breponernos al verdadero Dios. Hablar desde el hombre es hablar desde donde Dios concreta y definitivamente inmutabiliter nos ha interpelado ${ }^{16}$.

El reconocimiento de Jesús como el Cristo que es el fundamento de la fe cristiana tiene, además de su directo significado cristológico, una significación epistemológica que concierne a la teología cristiana en cuanto tal. Podría decirse que establece el horizonte y la perspectiva que debe guardarse en la búsqueda de inteligencia de la fe que le concierne a la teología. Así como Jesús no deja de ser hombre para hacerse Dios, sino que permanece como verdaderamente hombre y verdaderamente Dios, tampoco cabe un monologismo teológico ${ }^{17}$ que pretenda elaborar una teología al margen de la antropología que fundamenta el acontecer de Dios en la historia de Jesús.

Jesucristo, verdadero Dios y verdadero hombre, es el Theologos definitivo y perfecto de Dios que debe regir como patrón de toda teología cristiana. De alguna manera esto parecería haberlo intuido el escéptico Pilatos, quien, a pesar de dudar de la consistencia de la verdad (Jn 18, 3738), llega a reconocer en el rostro atormentado de Jesús al «ecce homo» (Jn 19, 5). Pues bien, la teología, en cuanto esfuerzo por pensar al verdadero Dios, no puede desentenderse del ecce homo, del verdaderamente hombre, al cual queda remitida como concreto Theo-logos. Solo en la historia de Jesús que culmina en su resurrección, Dios se dice perfectamente y esto determina a la teología en su condición de posibilidad. ¿De qué manera?

La teología se verifica como theologos y así alcanza su cometido cuando compromete al hombre no solo como mera individualidad subjetiva antecedente sino también en cuanto revierte sobre su misma subjetividad como determinación concernida por el objeto de fe: el verdaderamente hombre es el mismo verdaderamente Dios. Ahora bien, esta objetivización que se explicita en su fundamento cristológicamente se desvirtúa cuando se restringe a una jesuología ${ }^{18}$ y no considera ni explicita el significado universal que tiene en cuanto totalidad integrada pneumatológicamente. En realidad, la resurrección de Jesús no cierra la historia de Jesús en el pasado, sino que abre un futuro de resurrección para toda la

\footnotetext{
16 «Inconfuse, inmutabiliter, indivise, inseparabiliter» son los adverbios utilizados por el Concilio de Calcedonia para especificar el modo como la naturaleza humana y divina se relacionan en Jesucristo D.S. 302.

17 Este sería correlativo a un monofisismo cristológico.

18 Cf. A. ScHILSON, «Jesulogie» en Lexikon für Theologie und Kirche 5 (1996) 803-804.
} 
humanidad. Lo acontecido en Jesús se profundiza y universaliza positivamente como significado anticipado de la historia de toda la humanidad y así adquiere una dimensión cósmica y pneumática. El mismo Padre, el Creador es quien resucitó a Jesús y lo constituye Señor no al modo de un ídolo ensimismado o fetiche inerte, sino como Espíritu vivificante (1 Co 15, 45; 2 Co 3, 17). De allí que la cristología que no se proyecta en pneumatología se rige según un criterio parcial y abstracto de divinidad y no logra dar razón de la concretísima y universal extroversión amorosa que constituye el acontecer de Dios como Padre, Hijo y Espíritu. Dios no se acaba en Jesús como en un objeto o una cosa sino que en Él consuma su extroversión como Espíritu que afecta como tal y desde dentro -en cuanto interpelación libre a una creatura libre- a todos y cada uno de los hombres: «El Señor es Espíritu y donde está el Espíritu hay libertad» (2 Co 3, 17). Se trata del «Espíritu vivificante» (1 Co 15, 45) a través del cual actúa el resucitado $(\mathrm{Rm} 15,19)$ y que nos resucitará a nosotros mismos $(\mathrm{Rm} 8,11)$. El Espíritu es el don de Dios ${ }^{19}$ que hace presente y adelanta el futuro escatológico (Hch 2, 17 ss).

La dimensión pneumática no se contrapone a la cristológica sino que la prolonga en cuanto significa paso de una posibilidad al acto. El Espíritu actualiza en nosotros la esperanza que tiene en la resurrección de Jesucristo su condición de posibilidad. Una elaborada integración de ambas dimensiones, sin embargo, sigue siendo, al menos para la teología occidental, una tarea pendiente. Es en este sentido que Y. Congar reclama «por una cristología pneumatológica» ${ }^{20}$ que integre y no aísle la cristología de la pneumatología, y que W. Kasper apunta a una «nueva fundamentación de una cristología espiritual en perspectiva trinitaria $»^{21}$. La tarea de la que se trata es tan irrecusable como compleja: «La teología no puede substraerse sin más al frecuente reproche de haber olvidado el Espíritu. Sin embargo, la cristología será siempre más elocuente que la pneumatología incluso en el campo de la escatología donde el Espíritu desempeña un papel especial $\rangle^{22}$.

19 Hch 2, 38; 8, 20; 10, 45; 11, 17; Lc 11, 13; Gá 3, 2.5; Tt 3, 5.

20 Así el título de uno de los acápites de su obra de madurez El Espíritu Santo (Barcelona 1983) 598-607.

21 «Einer aus der Trinität. Zur Neubegründung einer spirituellen Christologie in trinitätstheologischer Perspektive» en M. BöHnKe - H. HeInz, Im Gespräch mit dem dreeinigen Gott (Düsseldorf 1985) 316-333.

22 W. Breuning, «Elaboración sistemática de la escatología», en Mysterium Salutis V (Madrid 1984), 759. 
Teología de y en la historia: sobre la pretensión historiológica de una teología ... $\mid 565$

El que la cristología necesariamente tenga que ser siempre más elocuente que la pneumatología es una afirmación más que discutible. Con ella podría justificarse indebidamente un déficit objetivo del occidente cristiano que ha sido denunciado con vehemencia, pero no sin razón, por la Iglesia de Oriente ${ }^{23}$. La integración de cristología y pneumatología no solo respondería a un imperativo ecuménico con respecto a las iglesias ortodoxas que no cabe postergar por más tiempo sino que descubrir al Espiritu como apunta Tertio millennio adveniente ( $\left.\mathrm{n}^{\circ} 45\right)$ comporta un requisito inalienable para que la Iglesia cumpla cabalmente su rol de evangelizadora, todavía mucho más si es preciso hacerlo en y no al margen de la $\operatorname{modernidad}^{24}$.

Me permito concluir recordando el párrafo final de las reflexiones que compartí con ustedes a propósito de Absolutezy relatividad del cristianismo: «La recepción de todo lo finito por parte del Dios de Jesucristo, no debería prestarse a una fetichización de instancias relativas dado el talante radicalmente escatológico y pneumático que tiene hablar de una absoluta relatividad del cristianismo; desde el punto de vista teológico, más bien, nos compromete y desafía positivamente a elaborar, aquí y ahora, una renovada y siempre provisoria teología de los signos de los tiempos» ${ }^{25}$.

Pues bien, teniendo en cuenta lo que acabamos de esbozar es posible que se perfile mejor la tarea que nos concierne:

23 Así por ejemplo, el teólogo ortodoxo V. Lossky, denuncia que en Occidente el Espíritu se esfuma y se hipertrofia la economía del Verbo. La vida cristiana solo puede ser concebida como imitación de Cristo y no más divinización operada por el Espíritu. A su juicio esto trae como consecuencia que el carisma sucumbe ante la institución, la libertad ante la autoridad, el profetismo ante el juridicismo, la mística ante la escolástica, el laicado ante el clero. El Espíritu se deforma como burda garantía de lo establecido. V. Lossky, Théologie mystique de l'Église d'Orient (París 1944). ${ }^{23}$ Cf. J. Z. SKIRA, «The Synthesis Between Christology and Pneumatology in Modern Orthodox Theology» en Orientalia Christiana Periodica 68 (2002) 435-465.

24 M. Bordoni delimita acertadamente este desafío cuando escribe: «comprender la urgencia para la situación actual del hombre religioso, de la profundización teológica en la relación entre cristología y pneumatología. En realidad, la cristología en cuanto discurso reflexivo de la fe sobre el misterio de Jesús como Cristo y Señor no puede desarrollarse sino en el lugar del Espíritu Santo, a pesar de que este lugar no haya sido siempre puesto en evidencia como habría merecido. La cuestión cristológica que ha tenido siempre como su principal motivo crítico el problema de Dios, se pone hoy día más específicamente como cuestión pneumatológica», La cristologia nell'orizonte dello Spirito (Brescia 1995) 12.

25 Teología y Vida 59 (2008) 202. 
Negativamente se supone una superación tanto del dualismo epistemológico que contrapone fe y razón, como del dualismo eclesiológico que confronta Iglesia y mundo. Ambos dualismos no dan cuenta de la unidad que valida la distinción y no logran pensar la intercompenetración que se da entre fe y razón e iglesia y mundo.

Positivamente, se impone un recentramiento pneumatológico que descosifica y dinamice extrovirtiendo el discurso teológico. Entonces, la Trinidad se piensa y constituye como unidad viva y dinámica que no se contrapone a la multiplicidad sino que la supone, en sí misma, como fecunda comunión originante y la sostiene, plenificándola desde sí misma por el Espíritu como multiplicidad originada. Así también se da cuenta, en toda su teológica radicalidad de la catolicidad de la Iglesia. La catolicidad no se fundamenta e impone según un paradigma externo y abstracto de uniformidad sino que es tal cuando se configura como vida que surge del seno de la misma Trinidad y se verifica en la creación. Por lo mismo, una teología de la catolicidad eclesial requiere pensar todo lo creado en cuanto realidad que, en su multiplicidad, se verifica escatológicamente. 
Teología de y en la historia: sobre la pretensión historiológica de una teología ... 567

Resumen: En la presente investigación, el autor analiza y articula los elementos para realizar una teología en la historia que, al mismo tiempo, se valide como una teología de la historia. Esta tarea impone un desafío que implica superar la contraposición fe-razón e Iglesia-mundo, por una parte, y, por otra, la necesidad de un recentramiento pneumatológico que descosifique y dinamice el discurso teológico.

Palabras clave: Teología en la historia, teología de la historia, catolicidad, recentramiento pneumatológico.

Abstract: In this study, the author analyzes and articulates elements for creating a theology in history that, at the same time, is validated as a theology of history. This task poses a challenge that entails overcoming the faith-reason and church-world opposition, on one hand, and, on the other, the need for a pneumatological re-centering that de-reifies and energizes theological discourse.

Keywords: Theology in history, theology of history, Catholicism, pneumatological re-centering. 